\title{
When Parents Divorce: A Protocol Suggestion in Cases of Adversial Divorces
}

\author{
Bernardelli Sara \\ SPC (School of Cognitive Psychotherapy)/APC (Association of Cognitive Psychology), Verona, Italy
}

\begin{abstract}
The experience of divorce influences life of children involved and there could be short- and long- term consequences (Dykeman, 2003). Researches showed that divorce can negatively change quality of attachment between children and parents, especially if maternal depression and high percentage of chronic conflict between parents attend (Fabbro, Bernardelli, Castagna, Domenichini, Gamba, \& Zanolla, 2009); negative effects could concern psychological well-being and school performance of children (Dykeman, 2003). Parents have difficulties to consider that when marital relationship is broken, they will always be parents: This process must be handled. The aim of the present work was to create a protocol for divorced families, where interventions for both parents and children are suggested. The main idea is that there are different phases in the divorce experience and each phase is characterized by specific interventions. The problem is to help families to find new ways to live "together" to grow children, where "to find” means "to create”. It is important to clarify reasons, stop conflicts and pass ambivalences (Vegetti Finzi, 2005).
\end{abstract}

Keywords: children, parents, divorce, intervention

\section{Introduction}

When we think about separation and divorce of parents, following words used by Giovanni Bollea (1995) could help us understand what is necessary to think about separation or divorce is a love story that finished and a money story that starts. If we think about these words, it is necessary to avoid that children stay between money and love, becoming victim of this double story (Bollea, 1995). The effects of parents divorce can have immediate and long-lasting consequences for children (Dykeman, 2003). Negative effects of divorce of parents depend on several factors, such as sex and age of children when divorce happens, conflict between parents and the possibility to cooperate between parents in taking care of children after divorce (Dacey \& Travers, 2002). Researches showed that divorce can negatively influence the quality of attachment relationship between children and parents, especially if some circumstances happen: high rate of conflict between parents and maternal depression (Fabbro et al., 2009); each of these factors, alone and in interaction with each other, influence the psychological well-being of the child and his/her ability to do well at school (Dykeman, 2003). The quality of relationship between parents before and after marriage could have a great impact on children, more than divorce itself (Hetherington, Stanley-Hagan, \& Anderson, 1989). Researches showed that high rate of conflict between parents predicts negative effects for both children and adults (Doolittle \& Deutsch, 1999;

Bernardelli Sara, psychologist, cognitive psychotherapist, SPC (School of Cognitive Psychotherapy) and APC (Association of Cognitive Psychology). 
Fabbro et al., 2009; Johnston, 1994; Johnston \& Campbell, 1988); moreover, if children are directly involved in the conflict, they will suffer more (Buchanan, Maccoby, \& Dornbusch, 1991; Grych \& Fincham, 1999; Johnston, 1993, 1994). Parents have difficulties to understand that marriage relationship can finished, but parental relationship continues and this implies a process; Bohannan (1970) has suggested six steps that are necessary to elaborate separation:

(1) Emotive divorce: Problems inside couple start;

(2) Legal divorce: Separation becomes official and legal proceeding starts;

(3) Economical divorce: It is characterized by discussion and agreement on properties and assets;

(4) Parental divorce: Roles and tasks for children are negotiated. Usually, it is characterized by high rates of conflicts between parents;

(5) Community divorce: Social relationships change; it is possible that strong lineless feelings appear;

(6) Psychological divorce: Aim of this stage is to find new projects and goals and to feel confident about the future.

If one of these steps failed, conflicts become chronic. It is also important to remember that before separation becomes concrete, three steps follow that influence psychological well-being of kids:

(1) Pre-separation: First signals of conflict inside the couple usually start six years before divorce. During this time, children understand that there is an emotional break between parents. This produces developmental problems, such as enuresis, tic, stutter, anxiety, psychosomatic symptoms (insomnia, headache, alopecia, asthma, etc.), and it could stress a relational disease, if it already exists before familiar crisis. Children could be worried to loose one parent; and they could take the side of one parent against the other. They live in an alert state permanently without safety (Bollea, 1995);

(2) Legal-controversial: Children feel anxious about temporary steps followed separation. Children live two different traumas: loss of omnipotence of parents, because a judge decides about their life; and fear to loose one parent that becomes reality (Bollea, 1995);

(3) Post-separation: Three or four years following separation are more crucial and dangerous for psychological well-being of kids. They suffer educational differences between parents and absence of one parent (usually father), in both cases, adversial separations or without conflict (Bollea, 1995).

Cigoli (1998) showed two typical steps that characterize family crisis: first named "pre-divorce" stage, which characterizes crisis of couple that could be followed by separation and "stepfamily" stage, in which there has been a new marriage or one for both parents. The problem is that there are not many clinical reflections about central phase of divorce, named "divorce therapy".

Many authors showed insufficient works about support and systematic help to people who are involved inside separation intervention (Bornstein \& Walters, 1988). Divorce is a psychopathological risk for children: This is the reason why children should be "first subject" of the separation, but not "object used" for separation. When children suffer hostility and conflict between parents and live economical controversial of them, they are at risk to develop psychological problems; also when there is not conflict, new type of family and educational rearrangements could create adaptation crisis for children (Bollea, 1995).

Finally, it is important to know that separation includes not only risk factors but also protective factors for children: (1) risk factors: presence of new partners, absence of explanations, social and domestic support absence; and (2) protective factors: preserving relationship with both parents, stability of models, good relationship between mother and child and/or between child and custodial parent. Presence of brothers and 
sisters who can be a model and allies, help from original families, new partners, give explanations to children about what is happened and what will happen (Malagoli Togliatti \& Lavadera, 2002).

The problem is that researches showed that children of divorced parents suffer consequences of separation showing depression, anger, anxious and withdrawal (Hess \& Camara, 1979) and cognitive, emotional and social problems (Hetherington, M. Cox, \& R. Cox, 1979a; 1979b).

Another important problem is the presence of maternal and paternal depression that influences relationship with children and their psychological well-beings (Fabbro et al., 2009; Spector, 2006).

Many studies showed that fathers develop loss and demoralization feelings during the periods following separation (Nielsen, 1999). More, fathers suffer more of depression compared to mothers following separation, especially because they usually feel guilty and suffer for anhedonia connected to no custody of children (Kendler, Thornton, \& Prescott, 2001).

Even maternal depression negatively influences psychological well-being of children, because it interferes with the quality of attachment relationship. Studies (Wallerstein \& Kelly, 1980; Allison \& Furstenberg, 1989; Clarke-Stewart, Vandell, McCartney, Owen, \& Booth, 2000) showed that if mother suffers depression following divorce experience, children show an insecure attachment relationship compared to children who live in intact families.

Another important event that often happens and influences psychological well-being of children is the creation of a new family by parents; stepmothers, stepfathers, stepsisters and stepbrothers could appear in life of children and they can feel like "half children". Studies showed that relationships between children and new wives and husbands are lived in a different way compared to biological relations (Ahrons, 2006). Another important task of these families is to define new roles and expectations of each person inside a new family; what is the role of a stepparent and a child who, at the same time, has a relationship with biological parent? So, stepfamilies face complex relational tasks that are difficult to manage (Cigoli, 1998).

Finally, the daily life of a stepfamily is difficult, because children have different domiciles where they spent a part of their life (home of the father or the mother); weekends and holidays that are spent with one parent or the other; their personal objects divided in two different houses; difficult decisions about important topics, such as school, etc. (Cigoli, 1998).

So, considering all these topics, treatments should help children understand what is happening in their families and how to cope with it; children should not experience negative effects of parents divorce and adults have to protect them from cognitive, emotional and behavioral consequences of divorce (Dykeman, 2003).

The aim of the present work was to suggest different steps that clinic can follow when work with these families.

\section{Protocol Suggestion in Work With Divorced Families}

The first thing to consider is to know what the specific step that each family is living is: pre-divorce or post-divorce (Kaslow \& Schwartz, 1987). This is important in order to create an intervention that is adapted to the specific step. This is important because emotions that people usually live during two steps are different and different therapeutic interventions are necessary. First is characterized by disillusionment, disaffection, anxiety and unbelief phase; second is "during divorce" phase, and third is "divorce" phase. It is, also, important to separate interventions for parents and for children. 


\section{Intervention for Parents}

\section{Define Therapeutic Contract}

The first step is to define a therapeutic contract with family to specify: Who take part in therapy session? Who pays? and Who can have access to information about therapy? (Lebow \& Rekart, 2007). Who takes part in therapy session? It is important to define this point in order to involve both mother and father and any other significant person who is involved and all children of the family. It is, also, important that all other family members who have a role inside the conflict are involved. In this step, it is important to define frequency and duration of sessions. Who pays? It is important to define this point because economic issues are important for these families. Who can have access to information about therapy? It is important that therapist guarantees in relation to the duty of confidentiality, i.e., that the information gathered during the course of treatment can not be given to people outside the therapy, unless there is an authorization signed by the participants so that confidentiality can be "violated".

\section{Therapeutic Alliance}

The construction of an adequate therapeutic alliance with all people involved in the therapeutic process is crucial in these families. As an alliance with each parent involved can easily be seen as an alliance against the other parent, considerable efforts are required to therapist to establish an impartial alliance (Boszormenyi-Nagy, 1974).

\section{Assessment}

In this phase, it is necessary to collect information on various topics. First, you need to know how long the couple is separated in order to know what stage they are living in. The action depends on whether the parents are in the first phase of disillusionment, alienation, anxiety, disbelief or in the second phase in which feelings of depression, detachment and anger, despair, confusion predominate, or in post-divorce phase dominated by feelings of resignation, optimism, curiosity, regret and sadness (Kaslow \& Schwartz, 1987). It is important to gather the family history, starting from the history of the parental couple. In this regard, the areas will be investigated are:

(1) Circumstances of first meeting of couple;

(2) Characteristics that influenced choice;

(3) Characteristics of relationship of the couple before the birth of the child: ask an example;

(4) Characteristics that they appreciated reciprocally;

(5) Characteristics they disappointed reciprocally;

(6) Family history;

(7) Present and past family atmosphere;

(8) Characteristics of personality of each family member: ask examples to explain it;

(9) Explanation of relations: ask examples to explain them;

(10) Physical and mental state of each parent;

(11) Looking for dysfunctional educational styles (Kendall \& Di Pietro, 1995);

(12) List of significant life events for each family member (Viaro, 2000).

It is important to note that some cautions are required when the assessment is made with divorced parents, because often the request for first consultation is made by the custodial parent, with which you can do first session. However, it is necessary that both parents give consent to psychological evaluation of the son.

In some cases, clinician can conduct interviews separately, especially when there is a high rate of conflict between parents and later he/she can propose joined sessions. The work with parents is essential to stimulate 
their collaboration.

Other information that is useful to collect is those regarding the presence of behavioral problems of children. In order to collect this information, clinician should ask:

(1) Critical events: detailed description of specific situations in which the problem occurred, investigating duration, intensity and frequency, considering the circumstances and the context in which the behavioral problem occurs;

(2) Collecting the functional analysis of the disorder to assess the reaction of parents when the child shows the behavior, in order to identify their roles in the evolution and maintenance of the problem;

(3) Analysis of the evolution of symptoms;

(4) Collecting psychological naives' theories (Lorenzini \& Sassaroli, 2000) about psychological disease and care of parents. Clinician can ask: "What are the signs and symptoms?", "How do you think led to this problem?” and "How do you think kept the problem?”. It is important to locate misperceptions, irrational beliefs, inappropriate behaviors, and also resources and personal skills;

(5) Assessing emotional dynamics within the family and parents' educational styles;

(6) Identifying the attempts made to solve the problem. It is necessary to meet parents individually, in order to create a space in which they can talk freely about their pain to assess whether the psychological problems could significantly interfere with parental responsibility. Through the technique of cognitive A: (situation), B: (beliefs) and C: (emotions/behaviors) (Ellis, 1994), it is important to collect significant information concerning the psychological health of parents to investigate presence of depression or any other feelings that may significantly interfere with parental role. The purpose of the assessment is to identify the strengths and challenges of family and treatment goals (Ackerman, 2001; Galatzer-Levy \& Kraus, 1999; Gould, 1998). An important point of the assessment is to evaluate if problems have individual basis and/or are made by circular process of the system. In the assessment phase, clinician can be supported by diagnostic tests:

(1) CBCL (children behavior checklist), 4-18 (Achenbach, 1991);

(2) DAYS (depression and anxiety in youth scale) by Newcomer, Barenbaum, and Bryant (1995);

(3) CDI (Children's Depression Inventory) (Kovacs, 1981);

(4) Functional analysis with attention to intensity, frequency and duration of the problem to highlight the child's behaviors and reactions of the environment.

\section{Intervention Strategies}

How to communicate with children. Children have many questions about what is happened in their families and no explanation will develop their ideas and feelings about what happened. Unfortunately, these can include feelings of guilt or considered in any way responsible for family breakdown. It is, therefore, important to create a context, because the child can share what initially may seem very confusing and fragmented story (Dowling \& Gorell Barnes, 2004). The questions parents must answer are: What kind of explanation they need and what the children will understand? And what is better to say and not? Adults must keep in mind that children need an explanation that is understandable and appropriate to their stage of development. For parents, it can be difficult to separate the explanation given to children by their feelings of grief, disappointment and loss. But, from the point of view of children, it is essential to make a clear distinction between the inability of the couple to live together and the continuity of parent-child relationship (Dowling \& Gorell Barnes, 2004). Even in clinical practice, we see that the fact of knowing that parents will no longer live 
in the same house but will continue to be parents, while creating suffering in children, however, is more useful for their silence, or because in the absence of communication; this will activate all the resources available to the grieving process. Parents must pay attention to children in communicating a decision that affects them deeply and will change their lives (Vegetti Finzi, 2005).

Psychoeducation. Psychoeducation is a very powerful intervention to help parents to solve many difficulties (Lebow \& Gurman, 1995). With couples in separation, it can be used to help them to understand processes involved in divorce and behaviors and emotions that usually characterize this experience. From their points of view, parents often blame the partners if children have normal post-divorce adjustment problems. Goals of psychoeducation intervention are different. First is to normalize the experience that they are living; to do this, clinician explains to parents that the problems they are experiencing are normal; then it is necessary to illustrate how both parents can support children through this difficult transition. Second objective is to explain the ways in which children may be involved in the dispute between parents (Lebow \& Newcomb Rekart, 2007). The aim of this stage is to make parents aware that children should remain outside the struggle between parents in order to protect them by development of insecure attachment in them (Cox \& Owen, 1993; Howes \& Markman, 1989; Waters et al., 1993). Another goal of psychoeducation interventions is to help parents focus on what is the best interest of children in family conflict (Lebow \& Newcomb Rekart, 2007). The therapist must use data from the literature on divorce to explain to parents the risks for children when parents are involved in protracted conflicts (Doolittle \& Deutsch, 1999; Fabbro et al., 2009; Grych \& Fincham, 1999). What does not seem clear to parents is that the constant presence and continuous conflict between them creates trauma in children who are the victims. The psychoeducation should also focus on helping parents to learn or improve parenting skills through parent training interventions (this topic will be detailed in the following paragraphs) (Lebow \& Newcomb Rekart, 2007).

Individual psychotherapy. Individual psychotherapy is important, if parents suffer from feelings of depression, anger, hopelesness and loneliness. Parents often have various problems that require a psychological diagnosis (Grych \& Finchman, 1999; Jenuwine \& Cohler, 1999), such as Axis I disorders and/or Axis II (DSM-IV-TR (diagnostic and statistical manual of mental disorders), 2000). In addition, although not present any diagnosable psychopathology, parents may be lacking in parenting skills (Doolittle \& Deutsch, 1999), have difficulties in separating their needs from the needs of their children to develop positive interaction with the other parents (Johnston, 1994; Johnston \& Campbell, 1988), or struggle to reorganize their lives after separation (Lebow \& Newcomb Rekart, 2007). This intervention is crucial to help parents achieve a greater psychological well-being and continues to maintain their parental role. In all these cases, psychological status of parents can negatively affect the attachment relationship with their children.

PT (Parent training). PT consists of a technical intervention involved parents in education, rehabilitation and psychotherapy, through teaching skills that are necessary to handle problems and situations with children (Fabbro, 2004). Use of PT intervention with parents is fundamental in the work with divorced couples, because the relationship between the parents and the child is always built on the basis of each other's contributions (Bowlby, 1975; Crittenden, 1994).

PT should be divided into two parts: First is informative and it is characterized by acquisition several information about risks for children and potential effects that this experience can have on them, including any protective factors (Isola \& Romano, 2007); Second is an educational-training, in which parents and clinician discuss about behavior-problem of children and find solutions, and work on cognitive aspects related to their 
self-efficacy and attributional styles and the aim is to encourage an alternative way to consider behavior of children and use effective strategies with children (Fabbro, 2004). Another goal of PT should be to increase awareness of parents about role of their behaviors on psychological well-being of kids. For this purpose, functional analysis is useful to identify factors involved: The focus is on what parents do and say and how these factors interact with children behavior (see Table 1).

Table 1

Functional Analysis

\begin{tabular}{|l|l|l|l|}
\hline \multicolumn{4}{|c|}{ Functional analysis } \\
\hline Antecedents: What is happening before & Behavior & Consequences: What I said & Consequences: What I did \\
\hline
\end{tabular}

Subsequently, there can be introduced problem-solving technique that is characterized by different steps followed by parents:

(1) To identify problems;

(2) To think about all hypothetical solutions;

(3) To balance the pros and cons of each solution;

(4) To select and implement the choice;

(5) To test effects (Fabbro, 2004).

Finally, one useful intervention is to ask parents to reflect on their beliefs, especially on the meaning they give to children' behaviors. The purpose of this stage is to reflect on dysfunctional and irrational beliefs of parents (for example: "My son must know that his father/mother has a lover, and this has let us down”), which can adversely affect the emotional state of children. Then, through cognitive disputing parents are helped by clinician to look for functional beliefs and alternative behaviors.

\section{Interventions for Children}

When parents separate, most children prefer that parents stay together: Sometimes, it is possible that they talk about their desires, but sometimes are unable to express it. Parental divorce may be experienced as a terrible loss, especially in relation to the parent who leaves the house. In addition, as a result of the reorganization family during and after the separation, there are many changes on their routines (Dowling \& Gorell Barnes, 2004). Therefore, it is important to create a context where child can share an experience that may seem very confusing and fragmented (Dowling \& Gorell Barnes, 2004). Children often suffer from specific psychopathology (Doolittle \& Deutsch, 1999), which may require specific attention and psychotherapy. But, even if you do not show a specific psychopathological disorder, children almost invariably show strong emotions, especially in relation to the presence of conflict between parents (Lebow \& Newcomb Rekart, 2007). Individual psychotherapy with the child (always combined with working with one or both parents) is important when parents are not psychologically available to work on them with a therapy (individual or family), when the children cannot separate their difficulties from problems of the parents and when child can benefit from a relationship with a therapist who is a figure not involved inside the conflict.

\section{Building Therapeutic Alliance}

When working with children/adolescents who live the experience of parental separation (but not only them), it is important to activate a process of empathy (Aringolo, 2008). Therapist must pay attention to verbal and nonverbal signals be able to take point of young client's view. Another important thought is that the 
therapists show an empathic attitude towards the child (Aringolo, 2008) without the interference of his/her thoughts and feelings. For this purpose, it is necessary that the therapists listen to the child, trying to understand his/her worldview and the perception he/she has of his/her reality. Being able to understand that for the child/teenager what is happened between the parents "is not acceptable", "is terrible”, "causes a very strong anger”, clinician must not interfere with his/her own point of view and/or beliefs. The most important thought is to listen to the child and pay attention to his/her feelings without judgments.

\section{Assessment}

The first phase of intervention will be necessary to understand what is the psychological state of the young client and investigate emotions and beliefs through $\mathrm{ABC}$ technique.

With children of primary school, it is recommended to collect the ABC through games (Di Pietro, 1999) (see Figure 1), while pre-adolescents and adolescents, you can use the psychological interview to gather information (see Table 2).

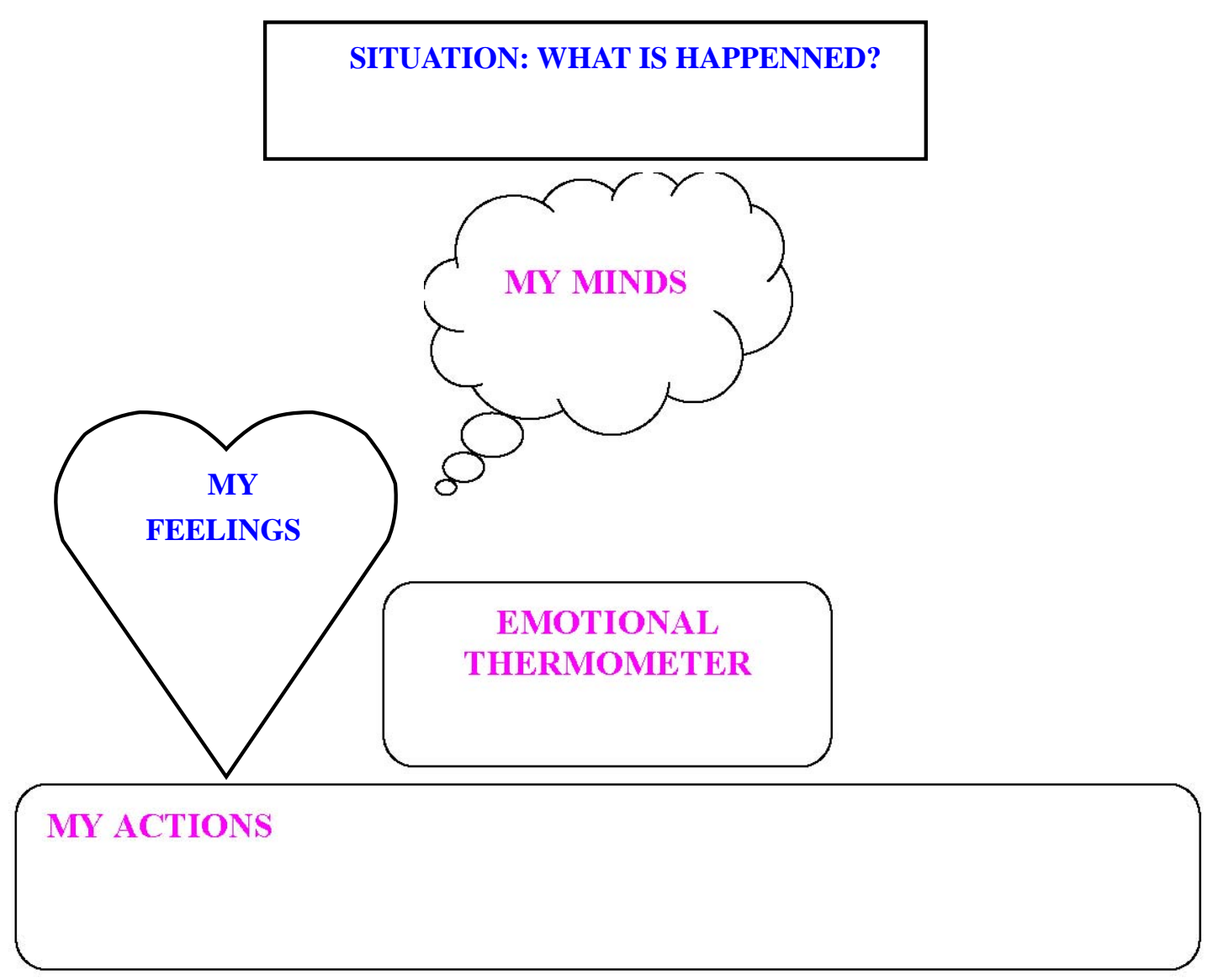

Table 2

Figure 1. Cognitive ABC with children.

Cognitive ABC With Adolescents

\begin{tabular}{|l|l|l|l|}
\hline Situation & $\begin{array}{l}\text { What I did think about? } \\
\text { (my minds, images, } \\
\text { etc.) }\end{array}$ & How did I feel? & What did I do? \\
\hline
\end{tabular}


During the first session, it is important to explain the role of the therapist and build therapeutic alliance. Following are specific areas to investigate:

(1) To investigate awareness of the child about what is happening, his/her ideas about divorce and, if he/she says, who is responsible for the separation;

(2) To collect emotions that child is living and describe for them. With this purpose, collecting ABC of the situation experienced by the child is useful. Clinician can also use stories that narrate about same situation experienced by the child to support conversation. It will be very important to focus on the problems that child talks about, for example, he/she may ask the reason why cannot see the father or the mother only a few days, or that he/she is not a clear division of the day visit, or want to see one parent (usually the one who does not live with him/her) more often, etc.. Therapist should be as an adult who trusts in, listens to and accepts requests of the child and subsequently will discuss with both parents about them;

(3) To understand how child perceives the problem: What do you fear might happen? What would happen if this happened and what it might mean for you? Why is it so bad?

(4) To ask the child how long is experiencing psychological pain;

(5) To retrace together with young client the experience of parental separation, focusing on the familiar atmosphere before the separation and family conditions that led to the separation. Clinician can ask about any fight to which the child may have witnessed or violence episodes against him/her or between parents, conflicts that may have accompanied his/her family experience before separation;

(6) To describe of how parents communicated about the separation: Did child receive a right explanation to his/her age? Parents were able to take feelings of child? Did child have the opportunity to ask what are they needed to parents?

(7) To describe how family has been reorganized after separation: What changes occurred? How did child experience it? Was the change gradual or unexpected?

(8) If there are new partners of parents to investigate how child experienced new figures;

(9) To assess the availability of the child to a possible therapeutic intervention; in addition, if necessary, therapist can ask child to make tests that investigate specific psychological disorders. If clients are adolescents, it is important to make them feel at ease and treat them as peers (Malagoli Togliatti \& Ardone, 1993).

Steps to follow are:

(1) To collect ABC to identify emotions and beliefs of young client;

(2) To assess the availability of the client to a possible therapeutic intervention if necessary. As for younger clients, clinician could purpose to complete some tests to investigate about specific psychological disorders;

(3) SAT (Separation Anxiety Test) (Main, Caplan, \& Cassidy, 1985; Hansburg, 1972; Reznick, 1993; Attili, 2001);

(4) DAYS (Depression and Anxiety in Youth Scale) (Newcomer, Barenbaum, \& Bryant, 1995);

(5) CDI (Kovacs, 1981): At the end of the first interview, you can ask the guy to make a self-monitoring of the behavior problem by compiling a diary of observation.

\section{The Importance to Receive an Explanation}

It is necessary to create a context where child can share what he/she is living at home. With some children, it can bring out the story through direct questions, but it is often helpful to use stories or play materials and 
designs to allow children to connect the experiences in a "mediated" context (Dowling \& Gorell Barnes, 2004). In working with children, we must take into account their age, so all information must be given in a way they can understand. When children are very young, it is important to use a simple and clear language. For example, they can have problems to understand word "divorce", but they can understand that the father will not live at home anymore. Around three years, the child will get an explanation of how this happened and are looking for explanations of the cause-effect. The adults will be asked to give a clear explanation that the child free from the feeling of being responsible for the decision or have the power to change decision of parents. At this age, we must pay particular attention to the fact that children can be worried about the thing that, since one parent has gone, the second one can do the same thing. Child could appear unable to stay far from one parent, awake during the night and ask to sleep in the bed with the parent enuresis and nightmares (Dowling \& Gorell Barnes, 2004). During the school years, children may feel confused about reasons of separation; they can feel an anger, betrayal or victims of an injustice for themselves or their parents. The school-age children can express their concerns and anxieties through a wide range of behaviors or physical symptoms: distraction in class, lack of interests in what happens around them and be appeared worried, they can show disruptive behaviors, or may become aggressive towards other children. Finally, adolescents often begin to manifest self-injurious behavior, alcohol or drugs abuse, problems at school connected to separation/divorce, changes of visits, remarriage of a parent, or to be in competition with "new" brothers and sisters. Some of adolescents exhibit extreme behaviors to show their anxieties in relation to what happened in the family (Dowling \& Gorell Barnes, 2004).

First, it is important to find the time and place that make the child feel safe enough to be able to discuss the situation at home. At this early stage, it is necessary to help parents be first reference which the children must refer to when they need to communicate about what is happened. Parents should be helped to understand that they must accept feelings, thoughts and concerns of children, create a present safe environment and also for the future. It is important that parents do not avoid pain of children; expressions like: "I noticed that you get angry more with your friends at school, something is wrong?", or "Sometimes, we find it hard to pay attention in school because there is something else that worries us is going to home..." maybe of useful expressions which address children. It is central to children be helped to make sense of changes in family life; having an explanation about what is happened is the first step for this, although they feel difficult to accept parents stay together anymore (Dowling \& Gorell Barnes, 2004).

\section{Emotions Experienced and Intervention Techniques}

Research shows that emotions that usually, children of separated parents live in are: anxiety, anger, sadness and guilt (Dowling \& Gorell Barnes, 2004). In the therapeutic process, the first step to do is to identify the emotions experienced by the child. If child is pre-school age, intervention must be conducted with parents. If child is at school age, however, you can start by talking about what is happened in their family, supporting by stories and human figure with the balloon to help the child to express their thoughts. With adolescents, however, you can use the clinical interview. All these tools are used to bring out the ABCs of the problematic situation and highlight what are the thoughts of the child or adolescent dysfunctional that they are doing to try specific emotions, thoughts of loss, sense of injustice, guilt, anxiety about the future. Then, psychoeducation intervention is used in order to explain ABC method and the relationship between beliefs and emotions and behaviors. Aim of this strategy is to normalize the emotional reactions of the young client. At this stage, it is useful to explain the idea of having two homes as a source of excitement rather than as a source of fear. To this 
end, the children must feel that they can contribute and be part of thereorganization process (Dowling \& Gorell Barnes, 2004). Then, child is asked to complete a "diary of the difficulties and emotions" (for example, to go to school, difficulties with friends, etc.). With this tool, child can learn more about how he/she feels and become aware of behaviors that put in place: The aim is to monitor beliefs, emotions and behaviors (Aringolo, 2008) (see Figure 2).

\section{MY ANGER}

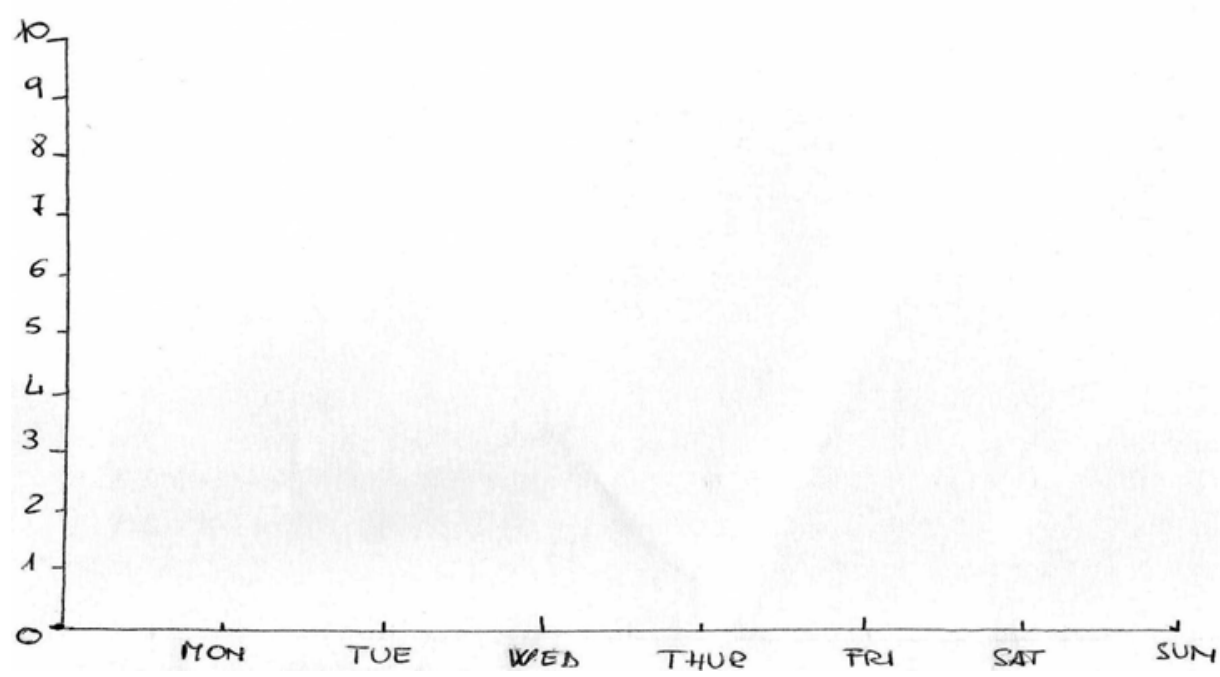

Figure 2. Table to monitor strenght of emotions everyday.

After highlighting the emotions and dysfunctional thoughts, it is useful to discuss with the child the contents of thoughts for the presence of irrational beliefs to become their functional beliefs. With teenagers, therapist can explain meaning of irrational beliefs, by giving a specific name in order to create a common vocabulary between therapist and child to enable them to understand what the thoughts that make young client feel bad are. Finally, therapist explains to young client how to challenge irrational beliefs through the discussion made during session to find alternative and functional beliefs. What has been said so far can be generalized to all the emotions felt by young clients. Below, we discuss some specific actions regarding the emotions that children can live.

\section{Specific Actions of Anger}

When children/adolescents show the emotion of anger through dysfunctional acting-out, it may be useful to provide them with specific strategies, both cognitive and behavioral, used to deal with crucial situations. Cognitive strategies that can be used are: self-dialogue, problem-solving, assertiveness training and the use of humor. The first strategy is to teach the child self-dialogue to reduce anger. The purpose is to teach the child how to reduce anger through verbal self-instructions to replace with their dialogues. Usually, this intervention changes emotional states and, consequently, behavioral responses to problem aticsituations (Capo, 2007). Another useful intervention is the use of humor with which children will interpose between the different cognitive situations that provoke anger and consequent behavior (Capo, 2007). Problem-solving training consists of different steps: understanding what the problem is, thinking about greatest number of solutions, 
indentifying what is the best, practicing it and to check if it works. For this purpose, clinician can suggest use of following steps: (1) stop: What's the problem?; (2) think: What can I do? Assumed the greatest numbers of alternative solutions; (3) identify: What is the best solution?; (4) do it: Try it; (5) check it: Did it work? Another useful intervention is assertiveness training which consists of teaching patients alternative responses to situations that typically evoke anger and aggressive reactions (Capo, 2007). The assertiveness training pursues several objectives: (1) To distinguish between aggressive, passive-aggressive and assertive reactions; (2) To identify personal rights in many interpersonal situations; (3) To identify and change irrational beliefs that produce passive and aggressive behaviors; and (4) To practice assertive behaviors to different situations that elicit anger (Саpo, 2007). Therapist can create cards that better explain assertiveness in order to attract the attention of the child and motivate him/her to work or to use materials already available in the literature to support the work and carry the child on the material discussed during the sessions (Di Pietro, 1999). Finally, a useful intervention is represented by the teaching of relaxation techniques that the young patient must learn and use when he/she feels strong anger. This is a specific behavioral technique. To apply it, it is important that young client is trained by therapist to recognize situations that are difficult by using a chart of anger and learning to use breathing for its management. It is necessary to remember that the use of these techniques is not straightforward and, indeed, often the first few times the patient may experience failures. Since there is a risk that, children feel demotivated if they do not have immediate results, it is useful to start to use techniques for simple situations and they get they can be wrong negative consequences.

The therapist, therefore, will have to arrange with the patient experiences gradual exposure to critical situations, where there is a chance to try new behaviors and observe and discuss the results together. In addition, the therapist can use role-playing sessions in which he/she and the patient alternately trying to put into practice the techniques discussed during session. This helps the child/adolescent to practice in a protected environment that is the therapist's office, and then use techniques in more complex situations.

\section{Specific Interventions on Depression}

During the experience of separation/divorce of their parents, children also feel sadness that can evolve into a feeling of depression itself due to the realization that his family will not be anymore accompanied by a difficulty to look towards the future. First, it is important to explain the cognitive ABC method, explaining the relationship between beliefs and emotions and dysfunctional behaviors, asking the patient to keep a weekly diary. As for anger, even depression, you can use the technique of role-playing together with role-taking (Aringolo, 2008). Specifically, through role-playing, an active patient learns and refines some behaviors in interactive situations, while, through role-taking, the patient learns to take the point of view of others. With the young depressed patients, these techniques are useful to stimulate their social skills, countering their negative expectations with respect to their interpersonal relationships (expectation of being rejected by others) (Aringolo, 2008). Other useful techniques are those aimed at enhancing behavioral skills (assertiveness, planning activities and the activation of positive images than the mental capacity to deal with various situations) in order to increase the metacognitive strategies of self-instruction, planning behavior and anticipate behavior. It will be useful to work with patients to increase problem-solving skills (see anger management interventions in the previous paragraph). Finally, it will be important to work on irrational beliefs making them rational. To do this, therapist can ask young client to think about his/her dear person (for example, a celebrity) thinking about real events that happened to him/her and empathize with him/her. 


\section{Specific Interventions to Guilt Emotion}

Often children of separated parents feel guilty, because they think they have a crucial role in the choice of parents. Often report phrases as: "I got dad angry because I did not want to wash myself, which is why he went away”. These beliefs make them feel responsible for what has happened to their family and feel a very strong feeling of guilt. This can emerge clearly especially in children whose thinking is characterized by self-centeredness that leads them to look at the center of the universe by taking the responsibility for the choices of others and feeling guilty about the negative consequences that occur (Vernon, 2002). During therapy, it is important to work on these minds through cognitive disputing and explaining to child that he/she is not responsible of divorce. In this regard, you may want to use the "pie chart" by entering all the possible reasons why the parents decided to separate and show the patient that does not depend on his/her behaviors. With older children and teens, it may also be useful to collaborate with parents, asking their availability to a sort of "interview" in which the young patient can give some questions to the parent in relation to his/her alleged responsibility in the choice taken from the parental couple. It is very important that children do not feel guilty because these beliefs can inhibit the behavior of the child/teenager, and also give rise to negative thoughts about themselves, such as the idea of "I am bad, that's the reason why they left", with severe consequences on the emotional state of the young patient.

\section{Work With Teachers}

Since, as it has been described in the introduction, the children of separated parents may have difficulty in school because of the events and emotions they live, may be useful to hold discussions with teachers. At first, it may be useful to meet with the teachers to collect information about behaviors of the child during school time to verify the presence of an uncomfortable situation. In this regard, therapist can use:

(1) Anamnestic clinical interview;

(2) Functional analysis of classroom behavior to get a clear picture of possible behavior problem: how long, when, how, with whom it expresses, frequency, intensity and duration of the behavior problem;

(3) Reactions of teachers at the behavior-problem;

(4) Naives theories of care and suffering of the teachers on the question of the pupil;

(5) Solutions already used and results;

(6) Activation of cooperation.

\section{References}

Achenbach, T. M. (1991). Manual for child behavior checklist, 4-18 and 1991 profile. Burlington: University of Vermont Department of Psychiatry.

Ackerman, M. J. (2001). Clinician's guide to child custody evaluations (2nd ed.). New York: Wiley.

Ahrons, C. R. (2006). Family ties after divorce: Long-term implications for children. Family Process, 26(1), 53-65.

Allison, P., \& Furstenberg F. (1989). How marital dissolution affects children: Variations by age and sex. Developmental Psychology, 25, 540-549

APA (American Psychiatric Association). (2000). Diagnostic and statistical manual of mental disorders. Elsevier.

Aringolo, K. (2008). Depression in infancy and adolescent: How it appears, how to evaluate, how to treat. Franco Angeli, Milano.

Attili, G. (2001). Separation anxiety and to measure normal and pathological attachment. Edizioni Unicopli, Milano.

Bohannan, P. (1970). Divorce and after: An analysis of the emotional and social problems of divorce. Garden City, N. Y.: Anchor. 
Bollea, G. (1995). Risks of familiar separation: Separation or divorce “imperfects” or “almost perfects”. In G. Bollea (Ed.), Mothers never fail (pp. 155-163). Saggi Universale Economica Feltrinelli, Milano.

Bornstein, P., \& Walters, H. A. (1988). Children of divorce: Empirical evaluation of a group-treatment program. Journal of Clinical Child Psychology, 17(3), 248-254.

Boszormenyi-Nagy, I. (1974). Ethical and practical implications of intergenerational family therapy. Psychotherapy and Psychosomatics, 24, 261-268.

Bowlby, J. (1973). Attachment and loss: Separation (Vol. 2). New York: Basic Books.

Buchanan, C. M., Maccoby, E. E., \& Dornbusch, S. M. (1991). Caught between parents: Adolescents' experience in divorced homes. Child Development, 62(5), 1008-1029.

Capo, R. (2007). Aggression and behavior problems: ODD and conduct disorder in childhood. In L. Isola, \& F. Mancini (Eds.), Cognitive psychotherapy in infancy and adolescence (pp. 296-349). Franco Angeli, Milano.

Cigoli, V. (1998). Psychology of separation and divorce. Il Mulino, Bologna.

Clarke-Stewart, K. A., Vandell, D. L., McCartney, K., Owen, M. T., \& Booth, C. (2000). Effects of parental separation and divorce on very young children. Journal of Family Psychology, 14(2), 304-326.

Cox, M. J., \& Owen, M. T. (1993). Marital conflict and conflict negotiation: Effects on infants mother and infant-father relationships. In M. Cox, \& J. Brooks-Gunn (Eds.), Conflict in families: Causes and consequences. Symposium conducted at The Meeting of the Society for Research in Child Development, New Orleans, L. A..

Crittenden, P. M. (1994). New perspectives about attachment. Milano: Guerini.

Dacey, J., \& Travers, J. (2002). Human development across the lifespan. Boston: MaGrawHill.

Di Pietro, M., (1999). ABC of emotions. Erickson: Trento.

Doolittle, D. B., \& Deutsch, R. (1999). Children and high conflict divorce: Theory, research, and intervention. In R. M. Galatzer-Levy, \& L. Kraus (Eds.), The scientific basis of child custody decisions (pp. 425-440). New York: Wiley.

Dowling, E., \& Gorell Barnes, G. (2004). To work with children and adolescents during separation and divorce of parents. Franco Angeli, Milano.

Dykeman, B. F. (2003). The effects of family conflict resolution on children classroom behavior. Journal of Instructional Psychology, 30(1), 41-46.

Ellis, A. (1994). Reason and emotion in psychotherapy. New York: Birch Lane Press.

Fabbro, N. (2004). Homeworks in parent training. In F. Baldini (Ed.), Homework: Anthology of therapeutic prescriptions (pp. 258-273). McGraw-Hill, Milano.

Fabbro, N., Bernardelli, S., Castagna, S., Domenichini, I., Gamba, F., \& Zanolla, E. (2009). Effects of separation and divorce of parents on quality of attachment of child. Cognitivismo Clinico, 6(1), 74-92.

Galatzer-Levy, R. M., \& Kraus, L. (Eds.). (1999). The scientific basis of child custody decisions. New York: Wiley.

Gould, J. W. (1998). Conducting scientifically crafted child custody evaluations. Thousand Oaks, C. A.: Sage.

Grych, J. H., \& Fincham, F. D. (1999). The adjustment of children from divorced families: Implications of empirical research for clinical intervention. In R. M. Galatzer-Levy, \& L. Kraus (Eds.), The scientific basis of child custody decisions (pp. 96-119). New York: Wiley.

Hess, R., \& Camara, K. A. (1979). Post-divorce family relationships as mediating factors in the consequences of divorce for children. Journal of Social Issues, 35(4), 79-96.

Hetherington, E. M., Cox, M., \& Cox, R. (1979a). Family interactions and the social emotional and cognitive development of children following divorce. In V. C. Gaughan, \& T. B. Brazelton (Eds.), The family: Setting priorities. New York: Science and Medicine Publishers.

Hetherington, E. M., Cox, M., \& Cox, R. (1979b). Stress and coping in divorce: A focus on women. In J. Gullahorn (Ed.), Psychology and women in transition. New York: Winston.

Hetherington, E., Stanley-Hagan, M., \& Anderson, E. (1989). Marital transitions: A child’s perspective. American Psychologist, 44, 303-312.

Howes, P., \& Markman, H. J. (1989). Marital quality and child functioning: A longitudinal investigation. Child Development, 60, 1044-1051.

Isola, L., \& Romano, G. (2007). Explanatory models of development and psychopathology: Role of attachment theory and developmental psychopathology. In L. Isola, \& F. Mancini (Eds.), Cognitive psychotherapy in infancy and adolescence. Franco Angeli: Milano. 
Jenuwine, M. J., \& Cohler, B. J. (1999). Major parental psychopathology and child custody. In R. Galatzer-Lary, \& L. Kraus (Eds.), The scientific basis of child custody decisions (pp. 285-318). New York: Wiley.

Johnston, J. R. (1993). Children of divorce who refuse visitation. In C. E. Depner, \& J. H. Bray (Eds.), Nonresidential parenting: New visitas in family living (pp. 109-135). Thousand Oaks, C. A.: Sage.

Johnston, J. R. (1994). High-conflict divorce. Future of Children, 4(1), 165-182.

Johnston, J. R., \& Campbell, L. E. G. (1988). Impasses of divorce: The dynamics and resolution of family conflict. New York: Free Press.

Kaslow, F., \& Schwartz, L. L. (1987). Dynamic of divorce, a life cycle perspective. New York, Brunner Mazel.

Kendall, P., \& Di Pietro, M. (1995). Scholastic therapy of anxiety. Erickson, Trento.

Kendler, K. S., Thornton, L. M., \& Prescott, C. A. (2001). Gender differences in the rates of exposure to stressful life events and sensitivity to their depressogenic effects. American Journal of Psychiatry, 158(4), 587-593.

Kovacs, M. (1981). CDI (Children’s Depression Inventory). Organizzazioni Speciali, Firenze.

Lebow, J. L., \& Gurman, A. S. (1995). Research assessing couple and family therapy. Annual Review of Psychology, $46,27-57$.

Lebow, J., \& Newcomb Rekart, K. N. (2007). Integrative family therapy for high-conflict divorce with dispute over child custody and visitation. Family Process, 46(1), 79-91.

Lorenzini, R., \& Sassaroli, S. (2000). Imprisoned mind: Strategies of cognitive therapy. Raffaello Cortina Editore, Milano.

Main, M., Kaplan, N., \& Cassidy, J. (1985). Security in infancy, childhood and adulthood: A move to level of representation. In I. Bretherton, \& E. Waters (Eds.), Growing points of attachment theory to research: Monographs of the society for research in child development (pp. 1-2).

Malagoli Togliatti, M., \& Ardone, R. (1993). Adolescents and parents. Nis, Roma.

Malagodi Togliatti, M., \& Lavadera, A. L. (2002). Relations dynamics and family life span. Il Mulino, Bologna.

Newcomer, P., Barenbaum, E., \& Bryant, B. (1995). DAYS (depression and anxiety in youth scale) PRO-ED. Austin, Texas.

Nielsen, L. (1999). Demeaning, demoralizing, and disenfrancising divorced diads: A review of the literature. Journal of Divorce and Remarriage, 31(3-4), 139-177.

Spector, A. Z. (2006). Fatherhood and depression: A review of risks, effects, and clinical application. Issues in Mental Health Nursing, 27, 867-883.

Vegetti Finzi, S. (2005). When parents divorce: Emotions of children. Oscar Saggi Mondadori, Milano.

Vernon, A. (2002). What works when with children and adolescents: A handbook of individual counseling techniques. Champaign, Illinois: Research Press.

Viaro, M. (2000). Problems during work with families, lesson at course: Integrated approach to personality disorders treatment. 20/5, Casa di cura Villa Margherita,Arcugnano (Vi).

Wallerstein, J., \& Kelly, J. (1980). Surviving the breakup: How children and parents cope with divorce. New York: Basic Brooks.

Waters, E., Merrick, S., Treboux, D., Crowell, J., \& Albersheim, L. (2000). Attachment security in infancyand early adulthood: A twenty-year longitudinal study. Child Development, 71(3), 684-689. 